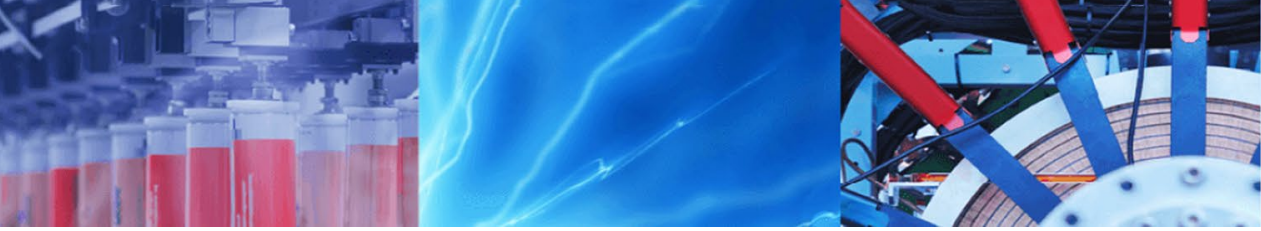

Research Article

\title{
Study of bagasse and cassava rhizome effects on the physical, mechanical and structural properties of soda-lime borate glasses
}

\author{
P. Sopapan ${ }^{1} \cdot$ R. Laopaiboon ${ }^{1} \cdot$ J. Laopaiboon ${ }^{1} \cdot$ P. Gunhakoon ${ }^{1} \cdot$ T. Thongklom ${ }^{2} \cdot$ O. Jaiboon ${ }^{1}$ (D)
}

Received: 14 February 2020 / Accepted: 7 April 2020 / Published online: 19 April 2020

(c) Springer Nature Switzerland AG 2020

\begin{abstract}
The glass prepared from sustainable raw materials yields interesting properties, besides the low cost and environmentally friendly. Two series of glass compositions based on $\mathrm{B}_{2} \mathrm{O}_{3}-\mathrm{P}_{2} \mathrm{O}_{5}-\mathrm{Na}_{2} \mathrm{O}-\mathrm{CaO}$ added with bagasse (BG) and cassava rhizome (CR) were fabricated by melt-quenching technique, and their physical, mechanical and structural properties were studied. The physical properties such as density and molar volume were calculated and discussed. The elastic moduli, Poisson's ratio, Debye temperature, acoustical impedance and microhardness have been estimated based on pressure-controlled ultrasonic technique at $4 \mathrm{MHz}$ frequency with normal and angle probes. It was found that the addition of bagasse and cassava rhizome leads to an increase of elastic constants, Debye temperature and microhardness of the prepared glass. Vickers hardness tester was also applied to determine microhardness of the glass using an applied load of $0.98 \mathrm{~N}$. The values of microhardness obtained from both techniques were compared and a good correlation was observed. Moreover, the internal structural units of the glass samples have been estimated by FTIR. XRD spectroscopy was applied to confirm the amorphous nature in the glasses.
\end{abstract}

Keywords Bagasse $\cdot$ Cassava rhizome $\cdot$ Glass $\cdot$ Pressure-controlled ultrasonic technique $\cdot$ Elastic constants · FTIR spectroscopy

\section{Introduction}

Biomass developed from agricultural production wastes and energy crops is discovered abundantly in nature, especially tropical countries like Thailand [1, 2]. Bagasse and cassava rhizome ashes are the biomass sources derived from valuable by-products in sugar extraction and waste of cassava fructification, respectively. However, incineration of bagasse and cassava rhizome as an energy source causes serious disposal problems, especially air pollution $\left(\mathrm{PM}_{2.5}\right.$ and $\left.\mathrm{PM}_{10}\right)[3,4]$. There are several studies of using bagasse and cassava rhizome ashes in many alternative applications such as production of glasses, ceramics, biocomposites, biomaterials, cements and concretes, etc. [5-8]. Converting these ashes into a glass system is one of alternative ways that may provide enormous benefits, because research in various capacities are being carried out on the applicability of glasses in various areas of glass applications such as biomaterials, radiation shields, optical devices, semiconductor microelectronics, etc. [9-11]. Bagasse and cassava rhizome ashes not only contain $\mathrm{SiO}_{2}$ and $\mathrm{CaO}$ that can be the main composition, but also contain some elements acting as a modifier oxide in glass network such as Al, Mg, $\mathrm{Sr}$, Ti, etc. (see in Table 1). Therefore, the replacement of pure raw materials by these agricultural wastes for fabrication of a glass system can be an interesting way in recycling these wastes.

Borate as glass host has received great attention and plays a key role for applying in many applications. It is one of technologically important groups of commercial

O. Jaiboon, oruethai.j@ubu.ac.th | 'Department of Physics, Faculty of Science, Ubon Ratchathani University, Ubon Ratchathani 34190, Thailand. ${ }^{2}$ Department of Industrial Engineering, Faculty of Engineering, Ubon Ratchathani University, Ubon Ratchathani 34190, Thailand. 
Table 1 Chemical compositions of bagasse and cassava rhizome by WDXRF method

\begin{tabular}{|c|c|c|}
\hline Compounds & Bagasse (wt\%) & $\begin{array}{l}\text { Cassava } \\
\text { rhizome } \\
\text { (wt\%) }\end{array}$ \\
\hline $\mathrm{MgO}$ & 1.430 & 16.300 \\
\hline $\mathrm{Al}_{2} \mathrm{O}_{3}$ & 5.990 & 1.230 \\
\hline $\mathrm{SiO}_{2}$ & 77.100 & 16.700 \\
\hline $\mathrm{P}_{2} \mathrm{O}_{5}$ & 0.900 & 12.100 \\
\hline $\mathrm{K}_{2} \mathrm{O}$ & 3.530 & 14.600 \\
\hline $\mathrm{CaO}$ & 5.180 & 37.080 \\
\hline $\mathrm{TiO}_{2}$ & 0.395 & 0.227 \\
\hline $\mathrm{Cr}_{2} \mathrm{O}_{3}$ & 0.019 & 0.034 \\
\hline $\mathrm{MnO}$ & 0.184 & 0.618 \\
\hline $\mathrm{Fe}_{2} \mathrm{O}_{3}$ & 5.181 & 0.787 \\
\hline $\mathrm{CuO}$ & 0.013 & - \\
\hline $\mathrm{ZnO}$ & 0.021 & 0.063 \\
\hline $\mathrm{SrO}$ & 0.016 & 0.226 \\
\hline $\mathrm{ZrO}_{2}$ & 0.040 & 0.036 \\
\hline Total & 100.000 & 100.000 \\
\hline
\end{tabular}

glasses owing to their unique characteristics which include a low melting point, a high thermal stability, transparency, mechanical and chemical durability [12-14]. In borate glasses, it is an established fact that boron is a laminar network consisting of three and/or four coordination numbers. Hence, the glassy $\mathrm{B}_{2} \mathrm{O}_{3}$ can have a triangle and/or tetrahedron forming three and four oxygen coordinated neighbors as structural units, and the high strengths of covalent $\mathrm{B}-\mathrm{O}$ bonds enables borates to form stable glasses $[15,16]$. However, the structure of borate glass not only depends on the network formers, but also on the additive's attendant in the constituent of glasses [17]. Introduction of some trace elements into glass network rearranges the glass internal structure by converting $\left[\mathrm{BO}_{3}\right]$ to $\left[\mathrm{BO}_{4}\right]$ structural units and leads to the formation of various borate groups. These additives also act as a modifier oxide in the glass matrix, and consequently an improvement their properties $[18,19]$. Therefore, borate glass system has been under intense research to understand the physical, mechanical, and structural properties through various experimental techniques.

Among the diverse methods required high precision, ultrasonic non-destructive technique is found to be the versatile tool for understanding the association of the structural characteristics and mechanical properties of amorphous materials [20]. The ultrasonic examination helps to understand the interatomic and ionic forces including the potentials in lattice structure [21,22]. The acoustic velocity as well as the density of glasses can be considered as parameters of elastic constants related directly to changes in the glass structure. Combined with the use of FTIR, the confirmation of the structural units of glass components has been received continuous attention. Moreover, this measurement can also describe the microhardness of materials, which is correlated directly with its strength, wear resistance and other mechanical properties $[23,24]$. As a result, hardness investigation by various techniques is widely considered for material evaluation. Since the values of elastic moduli and microhardness depended on an applied load, the design to control pressure on the ultrasonic measurement is required. Therefore, the consideration of the most appropriate glasses for specific application requires a knowledge of their mechanical and structural properties.

A spacious investigation has been carried out to study many properties in borate glass added with some pure elements. However, there are quite a few studies about new series of the borate glass prepared from bagasse and cassava rhizome. Therefore, the concept of this research is to introduce bagasse and cassava rhizome ashes as a component for glass system in order to maximize the use of resources. Preparation of the borate glasses with fly ash of bagasse and cassava rhizome was carried out by using rapid quenching method and in order to predict the mechanical and structural properties of these prepared glasses via the pulse-echo ultrasonic method. The pressure-controlled technique for measuring ultrasonic wave velocities was designed to control a suitable applied load. To compare and evaluate the accuracy of the microhardness, Vickers indentation has also been applied. Moreover, the glass structure has been confirmed by FTIR spectroscopy.

\section{Materials and methods}

\subsection{Bagasse and cassava rhizome characterization}

Ashes of bagasse and cassava rhizome were collected from electric power plant and agricultural plantation in northeast region of Thailand, respectively. Each ash was crush in an agate mortar and was graded to obtain particle size of $180 \mu \mathrm{m}$ using a sieve shaker machine. After that, the fly ashes of bagasse and cassava rhizome were calcined in an electric furnace for $1 \mathrm{~h}$ at 1073 and $1273 \mathrm{~K}$, respectively. The corresponding constituents of both wastes were analyzed by using WDXRF instrument (Panalytical, MagiX) with super sharp $\mathrm{x}$-ray tube (rhodium anode) and two detectors (gas-filled proportional and scintillation). The constituents of both ashes were listed in Table 1. 


\subsection{Sample preparation}

Two glass series of composition (68-x) $\mathrm{B}_{2} \mathrm{O}_{3}-3 \mathrm{P}_{2} \mathrm{O}_{5}-17 \mathrm{Na}_{2} \mathrm{O}-$ $12 \mathrm{CaO}-\mathrm{xBG}$ and $(68-\mathrm{x}) \mathrm{B}_{2} \mathrm{O}_{3}-3 \mathrm{P}_{2} \mathrm{O}_{5}-17 \mathrm{Na}_{2} \mathrm{O}-12 \mathrm{CaO}-\mathrm{xCR}$, where $\mathrm{x}=0,5$ and $10 \mathrm{wt} \%$, were prepared. These glasses were $\mathrm{fab}$ ricated from reagent-grade powders of $\mathrm{H}_{3} \mathrm{BO}_{3},\left(\mathrm{NH}_{4}\right)_{2} \mathrm{HPO}_{4}$, $\mathrm{Na}_{2} \mathrm{CO}_{3}$, and $\mathrm{CaO}$ as well as fly ashes of bagasse (BG) and cassava rhizome (CR), mixed together in appropriate amounts until obtaining homogeneous in alumina crucibles. The homogeneous mixture was then calcined and melted in an electrically heated muffle furnace under normal laboratory condition without controlling the atmosphere. Temperature range of 1373-1473 K, depending on the composition, for $2 \mathrm{~h}$-melting were employed to ensure the homogeneity before pouring onto a graphite block. Vitreous samples were then placed again into the furnace at appropriate temperature of $723 \mathrm{~K}$ for an annealing process to reduce any internal residual stress in the glass. After $2 \mathrm{~h}$, the furnace was switched off and such glass sample was allowed to cool slowly to environmental temperature. Glass samples with parallel flat and smooth surface were then obtained by cutting and polishing for ultrasonic velocity and Vickers hardness measurements.

\subsection{Density and molar volume studies}

A simple Archimedes' technique using $n$-hexane $\left(\mathrm{C}_{6} \mathrm{H}_{14}\right)$ as the reference worked liquid was used to determine density of the fragments of bulk glass. Knowing the apparent weight of the glass samples measured in air and reference fluid $\left(W_{a}\right.$ and $W_{r}$ ) allows us to calculate the density $(\rho)$ by the expression in Eq. (1) where $\rho_{r}$ is the density of $\mathrm{C}_{6} \mathrm{H}_{14}$ solution equal to $0.6600 \mathrm{~g} / \mathrm{cm}^{3}$. The obtained density and total atomic mass (M) of the glasses were applied to calculate the molar volume $\left(V_{a}\right)$ of the glass samples with Eq. $(2)[25,26]$.

$\rho=\rho_{r}\left(\frac{W_{a}}{W_{a}-W_{r}}\right)$

$V_{a}=\frac{M_{\text {glass }}}{\rho}$

The theoretical density and molar volume for borate glasses with correlation factor $99.4 \%$ can calculated by following expressions $[27,28]$ :

$$
\begin{aligned}
& \rho_{\text {cal }}=0.90 \sum_{i} \rho_{i} x_{i} \\
& V_{a}(c a l)=\sum_{i} \frac{M_{i} x_{i}}{\rho_{\text {cal }}}
\end{aligned}
$$

where $\rho_{\text {cal }}$ is the theoretical glass density, whereas $x_{i}$ and $M_{i}$ are the weight fraction and its molecular weight of the ith component respectively.

\subsection{Ultrasonic velocity and elastic modulus}

The suitable pressure-controlled ultrasonic method was applied to find the sound velocity values. The longitudinal $\left(v_{l}\right)$ and shear $\left(v_{s}\right)$ wave velocities were generated from SLG4-10 and SA04-45 transducer probes, respectively. Both velocities were operated at a fundamental frequency of $4 \mathrm{MHz}$ along with ultrasonic flaw detector (GE Phasor $\mathrm{XS}$ ) in mode A-scan, and a constant pressure of $0.98 \mathrm{~N}$ was also applied to control their pressures on the glass surface. The velocities of the studied glasses are obtained by measurement of the time intervals between transmission of the pulse and reception of the reply appearing directly on the monitor.

After receiving the density and sound velocity of the glass samples, elastic moduli $(L, G, K, E)$, Poisson's ratio $(\sigma)$, microhardness $(H)$ and Debye temperature $\left(\theta_{D}\right)$ were calculated in the following equations [10, 29]:

Longitudinal modulus: $L=\rho v_{I}^{2}$

Shear modulus: $G=\rho v_{s}^{2}$

Bulk modulus: $K=L-\left(\frac{4}{3}\right) G$

Young's modulus: $E=2(1+\sigma) G$

Poisson's ratio: $\sigma=\frac{L-2 G}{2(L-G)}$

Microhardness: $H=\frac{(1-2 \sigma) E}{6(1+\sigma)}$

Debye temperature: $\theta_{D}=\left(\frac{h}{K_{B}}\right)\left(\frac{9 N_{A}}{4 \pi V_{a}}\right)^{1 / 3} v_{m}$

where $h$ is the Planck's constant, $K_{B}$ the Boltzmann's constant, $N_{A}$ the Avogadro's number, and $v_{\text {mean }}$ the mean ultrasonic velocity defined by the expression:

$v_{\text {mean }}=\left(\frac{1}{3}\left(\frac{1}{v_{l}^{3}}+\frac{2}{v_{s}^{3}}\right)\right)^{-1 / 3}$

The transmitted and reflected sound waves in the glass samples is determined using the acoustical impedance (Z) 
which is determined as the multiplication between its density and mean velocity as following equation [24]:

$Z=\rho v_{\text {mean }}$

\subsection{Vickers hardness determination}

Figure 1 shows the geometry of Vickers indentation using a square-base diamond pyramid as the indenter with an angle of $136^{\circ}$ between opposite faces. This microhardness tester and ASTM standard (Mitsubishi, Mitutoyo MVK-H1) was applied to determine the Vickers hardness number $\left(H_{v}\right)$ of the glass samples at room temperature. An average of three values of each glass sample was taken and any crack is not observed on the indents of the glass surface. Then, the $H_{v}$ value was generally calculated directly as [30]:

$H_{v}=1.8544 \frac{F}{d^{2}}$

where $H_{v}$ is expressed in GPa, if the applied load $(\mathrm{F})$ is in N unit and $d$ is the arithmetic average of the diagonals of the indent $\left(d_{1}\right.$ and $\left.d_{2}\right)$ in $\mu \mathrm{m}$.



(a)

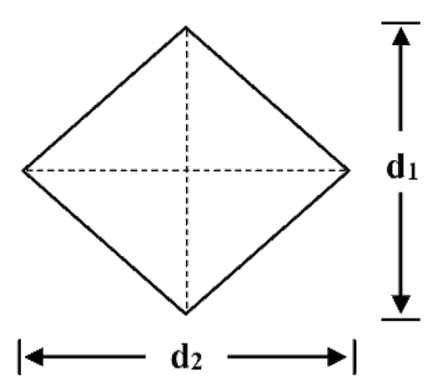

(b)

Fig. 1 The geometry of Vickers pyramid diamond indenter indentation

\subsection{XRD analysis}

The non-crystalline phase in the glasses was confirmed by using X-ray diffractometor ( $\mathrm{X}^{\prime}$ Pert Phillips) with $\mathrm{Cu}$ target and Ni filter. X'pert highscore plus software was applied to analyze the obtained data. In the XRD analysis, the diffractograms were recorded in $2 \theta$ range from $10^{\circ}$ to $70^{\circ}$ with a speed of $2^{\circ} / \mathrm{min}$.

\subsection{FTIR}

The IR transmission spectra of the prepared glasses have been carried out in the spectral range of $400-4000 \mathrm{~cm}^{-1}$ using FTIR spectroscopy (Thermo Scientific, Nicolet 6700). The samples for IR measurement were prepared by the $\mathrm{KBr}$ pellet method. In order to obtain good- quality spectra, the glass and $\mathrm{KBr}$ powders were crushed and mixed in an agate mortar to obtain small particles in the ratio of 1:100. Then, the homogeneous mixture was pressed under pressure of $5 \mathrm{ton} / \mathrm{cm}^{2}$ into a clear block with hydraulic pressure machine. Before the spectrum of all samples were recorded at ambient temperature, the blank $\mathrm{KBr}$ pellet was measured for the background spectrum.

\section{Results and discussion}

\subsection{Density and molar volume}

Density and molar volume are an important tool to understand the structural changes with composition of the glass. The structural changes include a geometrical configuration and an interatomic spacing of constituent atoms as well as the number of ions and the way by which ions can enter the glass network [31]. The experimental and theoretical values of density and molar volume of the whole glasses have been listed in Table 2. It was found that as the content of bagasse and cassava rhizome increased, the density of the prepared glasses increased while its molar volume decreased. This behavior indicates that the total molecular weight of bagasse and cassava rhizome is higher than the molecular weight of the borate agent in the glass system. Moreover, the substitution of $\mathrm{B}_{2} \mathrm{O}_{3}$ by the cassava rhizome yields the density values greater than that by the bagasse. This might be due to the change in the net molecular weight of its constituent component. The density and molar volume, generally, reveal adverse manner to each other. The decreased behavior in molar volume can be attributed to closing up of structure of glasses. Furthermore, the results of experimental density 
Table 2 Glass compositions, measured density $\left(\rho_{m}\right)$, calculated density ( $\left.\rho_{\text {cal }}\right)$, measured molar volume $\left(V_{a}\right.$ $(M))$, calculated molar volume $\left(V_{a}(c a l)\right)$ of studied glasses

\begin{tabular}{|c|c|c|c|c|c|c|c|c|c|c|}
\hline \multirow[t]{2}{*}{ Sample } & \multicolumn{6}{|c|}{ Composition (wt\%) } & \multicolumn{2}{|c|}{ Density $\left(\mathrm{g} / \mathrm{cm}^{3}\right)$} & \multicolumn{2}{|c|}{ Molar volume $\left(\mathrm{cm}^{3}\right)$} \\
\hline & $\mathrm{B}_{2} \mathrm{O}_{3}$ & $\mathrm{P}_{2} \mathrm{O}_{5}$ & $\mathrm{Na}_{2} \mathrm{O}$ & $\mathrm{CaO}$ & BG & $C R$ & $\rho_{m}$ & $\rho_{c a l}$ & $V_{a}(M)$ & $V_{a}(\mathrm{cal})$ \\
\hline GSO & 68 & 3 & 17 & 12 & - & - & 2.3403 & 2.3332 & 49.2197 & 49.3711 \\
\hline BGS1 & 63 & 3 & 17 & 12 & 5 & & 2.3550 & 2.3446 & 48.9029 & 49.1245 \\
\hline BGS2 & 58 & 3 & 17 & 12 & 10 & & 2.3857 & 2.3561 & 48.2646 & 48.8803 \\
\hline CGS1 & 63 & 3 & 17 & 12 & - & 5 & 2.3692 & 2.3534 & 48.6523 & 48.9944 \\
\hline CGS2 & 58 & 3 & 17 & 12 & - & 10 & 2.4051 & 2.3736 & 47.9563 & 48.6240 \\
\hline
\end{tabular}

$B G$ is the bagasse

$C R$ is the cassava rhizome and molar volume are in good agreement with the values of theoretical density and molar volume.

\subsection{Ultrasonic velocity, elastic modulus, Poisson's ratio, Debye temperature, and acoustical impedance}

The behavior of the acoustic velocities in borate glasses changes with the formation of glass network. Table 3 collects the ultrasonic velocities, elastic moduli, Poisson's ratio, Debye temperature, and acoustical impedance of the different glasses with respect to change in wt $\%$ of bagasse and cassava rhizome. As seen, from Table 3, the ultrasonic velocities increased with the contents of bagasse and cassava rhizome. It is well known that an increase in ultrasonic wave velocity in borate glass is associated with the switch of the trigonal $\mathrm{BO}_{3}$ to tetrahedral $\mathrm{BO}_{4}$ units, resulting in the increase of glass rigidity [32]. According to reports of Manupriya et al. [33] and Saddeek et al. [34], an increase of small amounts of $\mathrm{CaO}$ and $\mathrm{SiO}_{2}$ in borate glass led to the conversion of $\mathrm{BO}_{3}$ to $\mathrm{BO}_{4}$. This supported the increase in sound wave velocities in the glass. Likewise, the increase in both longitudinal and shear acoustic velocities of the glass samples in this study can be clarified by an increase of network-forming groups in the internal glass structure when the glass was partially substituted by bagasse (representative of $\mathrm{SiO}_{2}$ ) and cassava rhizome (representative of $\mathrm{CaO}$ ). The longitudinal and shear velocities of the bagasse-added glasses were found to change from 5786 to $6112 \mathrm{~m} / \mathrm{s}$ and 3405 to $3622 \mathrm{~m} / \mathrm{s}$, respectively. For the cassava rhizome-added glasses, both sound velocities increase from 5786 to $6005 \mathrm{~m} / \mathrm{s}$ and 3405 to $3571 \mathrm{~m} / \mathrm{s}$, respectively. It is clear that the bagasse-added glass yields the higher values of ultrasonic velocities than the cassava rhizome-added glass. This indicates that the glass containing bagasse can form the $\mathrm{BO}_{4}$ structure units more than that containing cassava rhizome when compared at the same content.

Then the ultrasonic velocities were applied to compute the elastic modulus, Poisson's ratio, Debye temperature, acoustical impedance and microhardness. According to Table 3, it was found that the longitudinal, shear, bulk, and Young's modulus of the glass samples increased with bagasse and cassava rhizome contents. The enhanced elastic modulus in the borate glass points out the increase in bonding strength in the borate structure [35]. Almost all elements of the bagasse are $\mathrm{SiO}_{2}$, while $\mathrm{CaO}$ is a most common representative in the cassava rhizome. Both substitutes can act as a network-forming groups in borate glass. When elements representing bagasse and cassava rhizome were added in the borate glasses, oxygen bond in the glass structure are formed. This may be led to the conversion of triangle to tetrahedron in structural units.

As well known, Poisson's ratio value has sensitive on the variation in glass network which include both changes in its cross-link density and dimension of the glass structure while Debye temperature supersedes the temperature at which nearly all the vibrational modes are excited [36, 37]. Both Poisson's ratio and Debye temperature can be computed by using ultrasonic velocities according to
Table 3 Ultrasonic velocities $\left(v_{l}, v_{s}, v_{\text {mean }}\right)$, elastic moduli $(L, G, K, E)$, Poisson's ratio $(\sigma)$, Debye temperature $\left(\theta_{D}\right)$ and acoustical impedance $(Z)$ of glass samples

\begin{tabular}{|c|c|c|c|c|c|c|c|c|c|c|}
\hline \multirow[t]{2}{*}{ Sample } & \multicolumn{3}{|c|}{$\begin{array}{l}\text { Ultrasonic velocities } \\
(\mathrm{m} / \mathrm{s})\end{array}$} & \multicolumn{4}{|c|}{ Elastic moduli (GPa) } & \multirow[t]{2}{*}{$\sigma \pm 0.001$} & \multirow[t]{2}{*}{$\theta_{D}(\mathrm{~K}) \pm 1$} & \multirow[t]{2}{*}{$\begin{array}{l}Z \times 10^{6}(\mathrm{~kg} / \\
\left.\mathrm{m}^{2} \mathrm{~s}\right) \pm 0.01\end{array}$} \\
\hline & $v_{l} \pm 3$ & $v_{s} \pm 5$ & $v_{\text {mean }} \pm 5$ & $L \pm 0.08$ & $G \pm 0.08$ & $K \pm 0.14$ & $E \pm 0.13$ & & & \\
\hline GSO & 5786 & 3405 & 3773 & 78.36 & 27.13 & 42.19 & 67.02 & 0.235 & 373 & 8.83 \\
\hline BGS1 & 5956 & 3524 & 3904 & 83.54 & 29.25 & 44.54 & 71.99 & 0.231 & 387 & 9.19 \\
\hline BGS2 & 6112 & 3622 & 4011 & 89.12 & 31.29 & 47.40 & 76.94 & 0.229 & 399 & 9.57 \\
\hline CGS1 & 5875 & 3482 & 3856 & 81.78 & 28.72 & 43.49 & 70.61 & 0.229 & 383 & 9.14 \\
\hline CGS2 & 6005 & 3571 & 3954 & 86.73 & 30.68 & 45.83 & 75.24 & 0.226 & 395 & 9.51 \\
\hline
\end{tabular}


Eqs. (9) and (11). The values of Poisson's ratio of all glass samples are less than 0.25 and almost constant values as the bagasse and cassava rhizome content increases. This indicates that a part of the energy results in the distortion of bond bending of the borate structure. Moreover, the addition of the bagasse and cassava rhizome increased the values of Debye temperature from 373 to $399 \mathrm{~K}$ and acoustic impedance from 8.83 to $9.57\left(\times 10^{-6}\left(\mathrm{~kg} / \mathrm{m}^{2} \mathrm{~s}\right)\right.$. In our glasses, Debye temperature presents a similar behavior to the dependency of glass composition with increase in weight fraction of bagasse and cassava rhizome. The increase in Debye temperature results in a monotonic increase in the total vibrational energy of the system. Acoustic impedance is significant in the determination of transmitted and reflected acoustic at the boundary of different materials and assessing absorption of sound in a medium. As well known, the sound wave travels through solid materials under the influence of sound pressure. The excess pressure leads to a wave propagating via the material because molecules of a solid are bound elastically to one another [38]. Therefore, the increase of acoustical impedance in our glasses indicates that our glasses can absorb more sound waves when bagasse and cassava rhizome content are increased.

\subsection{Microhardness}

Microhardness is an important parameter often used to specify the mechanical properties of a material on a

Table 4 Microhardness obtained from ultrasonic $\left(H_{U T}\right)$ and Vickers indentation $\left(H_{V}\right)$ techniques of glass samples

\begin{tabular}{llll}
\hline Sample & \multicolumn{2}{l}{ Microhardness (GPa) } & \%Difference \\
\cline { 2 - 3 } & $H_{U T} \pm 0.04$ & $H_{V} \pm 0.20$ & \\
\hline GS0 & 4.79 & 3.71 & 25.41 \\
BGS1 & 5.25 & 4.33 & 19.58 \\
BGS2 & 5.64 & 4.99 & 13.63 \\
CGS1 & 5.18 & 4.07 & 24.00 \\
CGS2 & 5.60 & 4.84 & 14.56 \\
\hline
\end{tabular}

microscopic scale. It suggested the disposed stress in its free volume and the dislocations deformation, or damage under an applied stress, and consequently its values depends on an applied load [23, 39]. The microhardness value has been evaluated using both pulse echo ultrasonic and Vickers indentation techniques for all the glasses. Tables 4 and 5 demonstrates the increase of microhardness of the studied glasses in both measurements as bagasse and cassava rhizome content increased. This increment may point out an increase in its rigidity by addition of bagasse and cassava rhizome content due to the conversion of $\mathrm{BO}_{3}$ into $\mathrm{BO}_{4}$ glass network. The values of microhardness in the glasses added with the bagasse is higher than that added with cassava rhizome. Moreover, the microhardness values obtained from the ultrasonic and Vickers techniques were consistent. The minimum and maximum percentage differences between both values were $13.63 \%$ and $25.41 \%$, respectively.

\subsection{X-ray diffraction (XRD) analysis}

The non-appearance of sharp diffraction peaks in the typical XRD patterns indicates the absence of long-range atomic arrangement confirming the amorphous phase in the studied glasses as displayed in Fig. 2. According to the figure, the five glass samples exhibit similar XRD patterns and two broad humps are clearly observed. The formation of two amorphous phases with different intensities in the XRD patterns has been depicted by phase separation. The major mechanisms for phase separation, generally, are termed spinodal decomposition, nucleation and growth $[40,41]$. The first broad hump was found between $15^{\circ}<2 \theta<35^{\circ}$ which confirms strongly amorphous nature (short-range order) of all the glass samples. The medium range order is received from the XRD patterns which exhibit either a pre-hump on the low angle side of the main peak or a more developed first diffraction peak [42]. Thus, another broad band with lower intensity was observed in the angle range of $40-50^{\circ}$, implying the presence of another phase with medium-range order. Similar observation of two broad bands in sodium borate glasses
Table 5 Assignment of absorption bands in the infrared spectra of glass system

$$
\begin{aligned}
& 3200-3600 \\
& 2300-2400 \\
& 1632 \\
& 1200-1500 \\
& 900-1100 \\
& 680-730 \\
& 708 \\
& 400-600
\end{aligned}
$$

\section{Assignment}

Water, $\mathrm{H}-\mathrm{O}-\mathrm{H}, \mathrm{Si}-\mathrm{OH}$ vibrations

Carbonate groups $(\mathrm{C}-\mathrm{H})$

Indicates that $\mathrm{BO}_{3}$ changes to $\mathrm{BO}_{4}$ and Hydrogen bonding

$\mathrm{B}-\mathrm{O}-\mathrm{B}$ in $\mathrm{BO}_{3}$ triangles

$\mathrm{B}-\mathrm{O}$ bond stretching of tetrahedral $\mathrm{BO}_{4}$ units

$\mathrm{B}-\mathrm{O}-\mathrm{B}$ in $\mathrm{BO}_{3}$ triangles

Bending vibrations of $\mathrm{Si}-\mathrm{O}-\mathrm{B}$ bridges and $\mathrm{B}-\mathrm{O}-\mathrm{B}$ in $\mathrm{BO}_{3}$ units

$\mathrm{Si}-\mathrm{O}-\mathrm{Si}, \mathrm{O}=\mathrm{P}-\mathrm{O}$ linkages and Modifier cation vibrations 
Fig. 2 X-ray diffraction (XRD) patterns for $\mathrm{B}_{2} \mathrm{O}_{3}-\mathrm{P}_{2} \mathrm{O}_{5}-\mathrm{Na}_{2} \mathrm{O}-$ $\mathrm{CaO}$ glass with different mix proportions of bagasse and cassava rhizome

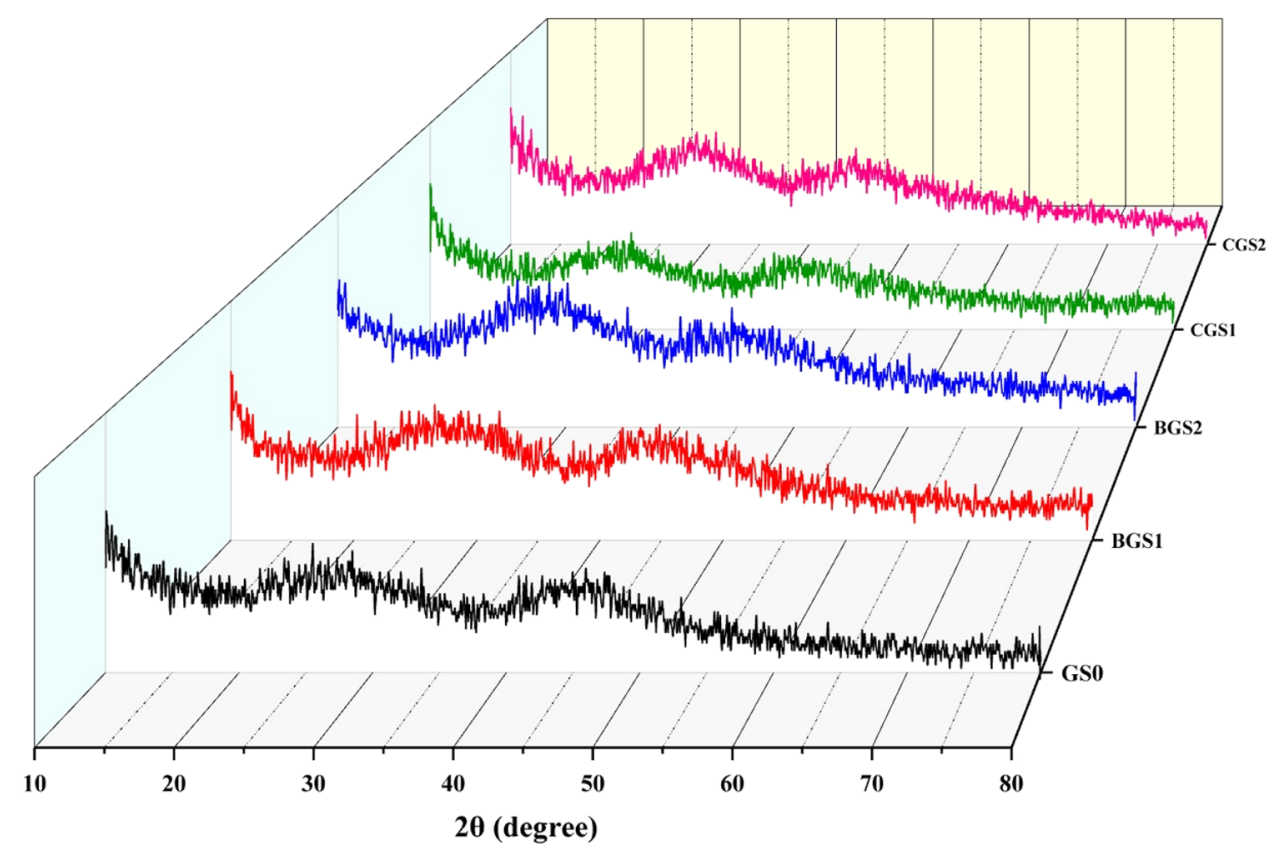

has also been reported by Alajerami et al. [43]. However, the lack of apparent changes in the bands between the glass samples suggested that the small addition of bagasse and cassava rhizome has no significant effect on phase separation.

\subsection{FTIR}

The IR spectroscopy is a powerful analysis tool for confirming the internal structural transformations in a glass material. Under changes the glass composition, the IR spectra have been recorded to understand the changes of a specific vibrational mode of glass structure due to the process of structural grouping rearrangements $[22,44]$. The infrared spectra of the selected glasses in the region rang of $400-4000 \mathrm{~cm}^{-1}$ presented in Fig. 3. These spectra showed three main groups of vibrational modes in the areas of $600-700 \mathrm{~cm}^{-1}, 800-1200 \mathrm{~cm}^{-1}$, and $1200-1500 \mathrm{~cm}^{-1}$. As Fig. 3 , it is observed that the vibrational peak values were positioned at $\sim 442, \sim 566, \sim 708, \sim 960, \sim 1085, \sim 1225, \sim 1$ $382, \sim 1632, \sim 2369, \sim 3289, \sim 3442$, and $3529 \mathrm{~cm}^{-1}$ in all the glasses. However, other weaker bands observed at various frequencies $\left(400-500 \mathrm{~cm}^{-1}\right.$ ) are also presented after the glass sample was added with bagasse and cassava rhizome.

The absorption peaks around $400-600 \mathrm{~cm}^{-1}$ are attributed to the $\mathrm{Si}-\mathrm{O}-\mathrm{Si}$ and bending vibration of $\mathrm{O}=\mathrm{P}-\mathrm{O}$ linkages overlapped by the vibration of metal cations $\left(\mathrm{Ca}^{2+}\right.$,
$\mathrm{Mg}^{2+}, \mathrm{Al}^{2+}, \mathrm{Na}^{2+}, \mathrm{Zn}^{2+}$, etc.) in their respective sites within the glass network $[45,46]$. From the spectra in Fig. 3 , it is obviously observed that there are a greater number of peaks observed in this region with addition of bagasse and cassava rhizome contents. This apparently predicates an increase in $\mathrm{SiO}_{4}$ units and the cationic vibrations in the network with increase in bagasse and cassava rhizome content.

It is generally accepted that broad bands in region of $680-730 \mathrm{~cm}^{-1}$ and $1200-1500 \mathrm{~cm}^{-1}$ are attributed to bending and stretching vibrations of $\mathrm{B}-\mathrm{O}-\mathrm{B}$ in $\mathrm{BO}_{3}$ triangles of the boron-oxygen network, respectively $[47,48]$. The peak at about $708 \mathrm{~cm}^{-1}$ is due to the vibrations of $\mathrm{B}-\mathrm{O}-\mathrm{Si}$ bridges [49]. The vibrational area at $900-1100 \mathrm{~cm}^{-1}$ originates from $\mathrm{B}-\mathrm{O}$ bond stretching of tetrahedral $\mathrm{BO}_{4}$ units in various structural groups [50].

In our glass system, the decrease of intensity of observed broad bands in areas at $680-730 \mathrm{~cm}^{-1}$ and $1200-1500 \mathrm{~cm}^{-1}$ indicates that the conversion of $\mathrm{BO}_{3}$ into $\mathrm{BO}_{4}$ units, and the conversion can be enhanced by increasing bagasse and cassava rhizome contents. In addition, the peak at roughly $1632 \mathrm{~cm}^{-1}$ is indicated the transformation of $\mathrm{BO}_{3}$ into $\mathrm{BO}_{4}$ units [51], and also this peak may be assigned to the deformation modes of $\mathrm{O}-\mathrm{H}$ groups and water molecules [52]. As well as the consideration of many researches, the IR absorption region extending from 2300 to $3600 \mathrm{~cm}^{-1}$ are originating from hydrogen bonding, carbonate and $\mathrm{OH}$ groups $[53,54]$. 
Fig.3 IR spectra of studied glasses with different mix proportions of bagasse and cassava rhizome

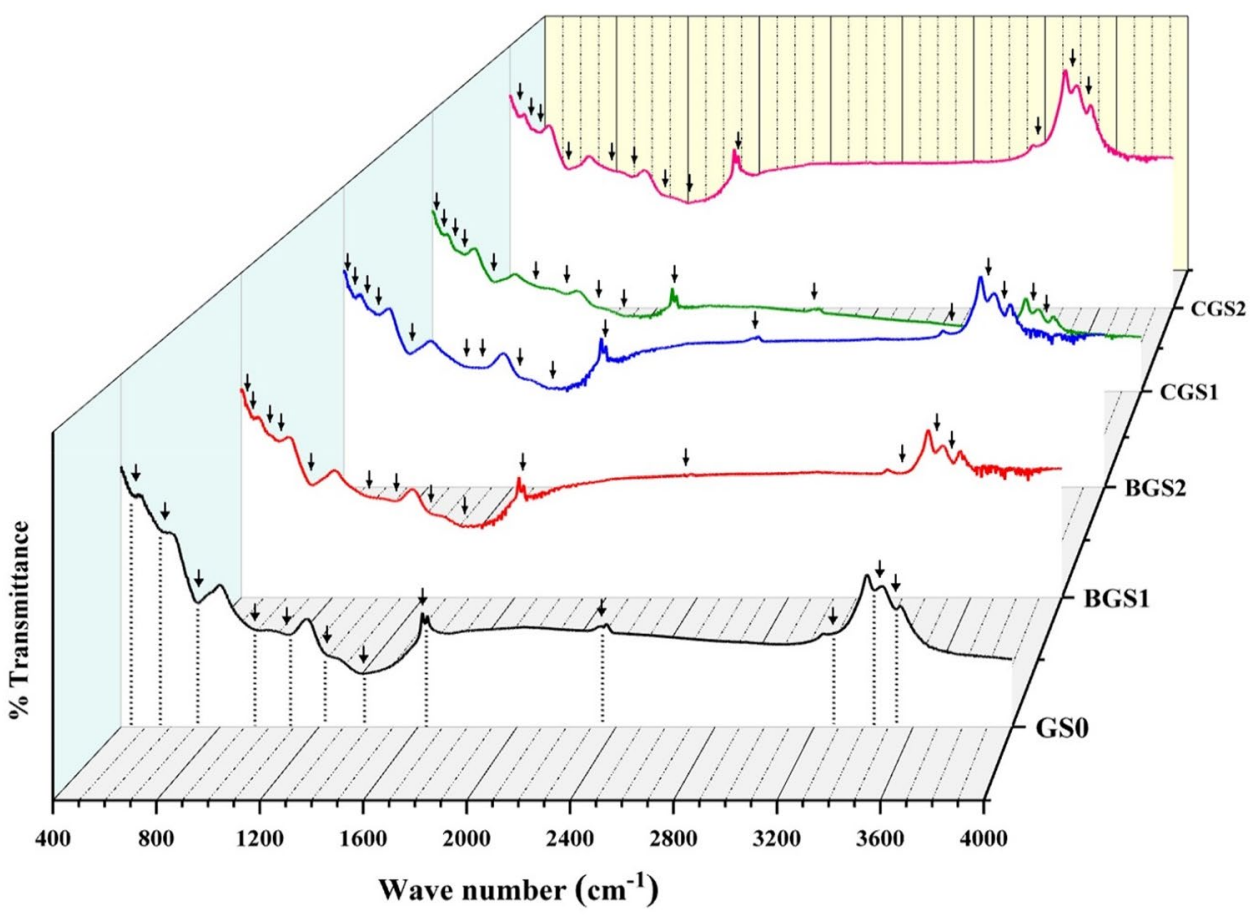

\section{Conclusions}

Two series of the glass were successfully fabricated by the addition of treated bagasse and cassava rhizome with $0-10$ wt $\%$. The effects of bagasse and cassava rhizome in $\mathrm{B}_{2} \mathrm{O}_{3}-\mathrm{P}_{2} \mathrm{O}_{5}-\mathrm{Na}_{2} \mathrm{O}-\mathrm{CaO}$ glass systems were evaluated to predict their physical, mechanical and structural properties. The XRD patterns confirmed the amorphous phase in all the glass. From FTIR measurement, vibrational intensity of $\mathrm{BO}_{3}$ trigonal units in the broad band regions at $680-730 \mathrm{~cm}^{-1}$ and $1200-1500 \mathrm{~cm}^{-1}$ decreased while the number of peaks of modification vibrations in region range $400-600 \mathrm{~cm}^{-1}$ increased as the bagasse and cassava rhizome contents. These suggest the conversion of $\mathrm{BO}_{3}$ into $\mathrm{BO}_{4}$ by addition of bagasse and cassava rhizome to borate glass. This supports the results from ultrasonic testing that the partial replacement of $\mathrm{B}_{2} \mathrm{O}_{3}$ by bagasse and cassava rhizome leads to the increase of acoustic velocities, elastic moduli, Debye temperature, acoustical impedance and microhardness in the glasses due to the formation of glass network by converting $\mathrm{BO}_{3}$ to $\mathrm{BO}_{4}$ units. Furthermore, it is suggested that the microhardness values of the proposed glass obtain from ultrasonic technique are in good agreement with Vickers indentation method.
Acknowledgements The authors wish to express their thanks to the Department of Physics and Department of Industrial Engineering, Ubon Ratchathani University, Thailand for measurements of ultrasonic velocity and Vickers hardness, respectively. This research was supported by the Science Achievement Scholarship of Thailand (SAST).

\section{Compliance with ethical standards}

Conflict of interest The authors declare that they have no known competing financial interests or personal relationships that could have appeared to influence the work reported in this paper.

\section{References}

1. Chindaprasirt P, Sujumnongtokul P, Posi P (2019) Durability and mechanical properties of pavement concrete containing bagasse ash. Mater Today Proc 17:1612-1626

2. Kuprianov VI, Se C, Ninduangdee P (2019) The influence of fluidized bed co-combustion of cassava rhizome and eucalyptus bark on the combustor performance and time-related physiochemical changes of the bed material. Biomass Bioenerg 127:105250

3. Silva FS, Cristale J, André PA, Saldiva PHN, Marchi MRR (2010) $\mathrm{PM}_{2.5}$ and $\mathrm{PM}_{10}$ : the influence of sugarcane burning on potential cancer risk. Atmos Environ 44:5133-5138 
4. Lee $\mathrm{HH}$, Iraqui $\mathrm{O}$, Wang C (2019) Impact of future fuel consumption on regional air quality in southeast asia. Sci Rep 9:2648

5. Sharma G, Singh K (2019) Recycling and utilization of agro-food waste ashes: syntheses of the glasses for wide-band gap semiconductor applications. J Mater Cycles Waste 21:801-809

6. Bahurudeen A, Kanraj D, Dev VG, Santhanam M (2015) Performance evaluation of sugarcane bagasse ash blended cement in concrete. Cement Concr Comp 59:77-88

7. Baharuddin $\mathrm{NH}$, Mohamed $\mathrm{M}$, Abdullah MMAB, Muhammad N, Rahman R, Omar MN, Amini MHM, Razab MKAA, Rizman ZI (2016) Potential of cassava root as a raw material for bio composite development. ARPN J Eng Appl Sci 11:6138-6147

8. Santos DT, Sarrouh BF, Rivaldi JD, Converti A, Silva SS (2008) Use of sugarcane bagasse as biomaterial for cell immobilization for xylitol production. J Food Eng 86:542-548

9. El-bashir BO, Sayyed MI, Zaid MHM, Matori KA (2017) Comprehensive study on physical, elastic and shielding properties of ternary $\mathrm{BaO}-\mathrm{Bi}_{2} \mathrm{O}_{3}-\mathrm{P}_{2} \mathrm{O}_{5}$ glasses as a potent radiation shielding material. J Non-Cryst 468:92-99

10. Halimah MK, Umar SA, Chan KT, Latif AA, Azlan MN, Abubakar Al, Hamza AM (2019) Study of rice husk silicate effects on the elastic, physical and structural properties of borotellurite glasses. Mater Chem Phys 238:121891

11. Kaur $R$, Singh $S$, Pandey OP (2012) TIR structural investigation of gamma irradiated $\mathrm{BaO}-\mathrm{Na}_{2} \mathrm{O}-\mathrm{B}_{2} \mathrm{O}_{3}-\mathrm{SiO}_{2}$ glasses. Phys $\mathrm{B}$ 407:4765-4769

12. Halimah MK, Eevon $C$ (2019) Comprehensive study on the effect of $\mathrm{Gd}_{2} \mathrm{O}_{3}$ NPs on elastic properties of zincborotellurite glass system using non-destructive ultrasonic technique. J Non-Cryst 511:10-18

13. Krishnamacharyulu N, Mohini GJ, Baskaran GS, Kumar VR, Veeraiah $\mathrm{N}$ (2016) Effect of $\mathrm{ZrO}_{2}$ on the bioactive properties of $\mathrm{B}_{2} \mathrm{O}_{3}-\mathrm{SiO}_{2}-\mathrm{P}_{2} \mathrm{O}_{5}-\mathrm{Na}_{2} \mathrm{O}-\mathrm{CaO}$ glass system. J Non-Cryst 452:23-29

14. Lucacel RC, Ponta O, Licarete E, Radu T, Simon V (2016) Synthesis, structure, bioactivity and biocompatibility of melt-derived $\mathrm{P}_{2} \mathrm{O}_{5}-\mathrm{CaO}-\mathrm{B}_{2} \mathrm{O}_{3}-\mathrm{K}_{2} \mathrm{O}-\mathrm{MoO}_{3}$ glasses. J Non-Cryst 439:67-73

15. Koudelka $L$, Kalenda $P$, Mošner $P$, Černošek $Z$, Montagne $L$, Revel $\mathrm{B}$ (2016) Structural investigation of $\mathrm{BaO}-\mathrm{B}_{2} \mathrm{O}_{3}-\mathrm{P}_{2} \mathrm{O}_{5}$ glasses by NMR and Raman spectroscopy. J Mol Struct 1119:212-219

16. Möncke D, Tricot G, Beckmann AW, Wondraczek L, Kamitsos EI (2015) On the connectivity of borate tetrahedra in borate and borosilicate glasses. Phys Chem Glasses 56:203-211

17. Balachander L, Ramadevudu G, Shareefuddin M, Sayanna R, Venudhar YC (2019) IR analysis of borate glasses containing three alkali oxides. Sci Asia 39:278-283

18. Palani R, Selvarasi J (2017) Thermal and structural properties of borate lithium glass doped with potassium oxide and calcium oxide. Int J Curr Res Rev 5:48-55

19. Saddeek YB, Gaafar MS (2009) Physical and structural properties of some bismuth borate glasses. Mater Chem Phys 115:280-286

20. Palani R, Selvarasi J (2017) Elastic and structural properties of potassium and calcium-doped borate lithium glasses. Int J Curr Res Rev 9:71-79

21. Saddeek YB, Azooz MA, Saddek AMRB (2015) Ultrasonic investigations of some bismuth borate glasses doped with $\mathrm{Al}_{2} \mathrm{O}_{3}$. Bull Mater Sci 38:241-246

22. Hasnimulyati L, Halimah MK, Zakaria A, Halim SA, Ishak M (2017) A comparative study of the experimental and the theoretical elastic data of $\mathrm{Tm}^{3+}$ doped zinc borotellurite glass. Mater Chem Phys 92:228-234

23. Patil AL (2017) Measurements of Vickers hardness and refractive index properties of Na-borophosphate glasses. Int J Chemtech Res 10:138-142
24. Elkhoshkhany N, El-Mallawany $\mathrm{R}$, Syala $\mathrm{E}$ (2016) Mechanical and thermal properties of $\mathrm{TeO}_{2}-\mathrm{Bi}_{2} \mathrm{O}_{3}-\mathrm{V}_{2} \mathrm{O}_{5}-\mathrm{Na}_{2} \mathrm{O}-\mathrm{TiO}_{2}$ glass system. Ceram Int 42:19218-19224

25. Sopapan P, Laopaiboon J, Jaiboon O, Yenchai C, Laopaiboon R (2020) Feasibility study of recycled CRT glass on elastic and radiation shielding properties used as $\mathrm{x}$-ray and gamma-ray shielding materials. Prog Nucl 119:103149

26. Ahmed AA, Ali AA, El-Fiqi A (2019) Glass-forming compositions and physicochemical properties of degradable phosphate and silver-doped phosphate glasses in the $\mathrm{P}_{2} \mathrm{O}_{5}-\mathrm{CaO}-\mathrm{Na}_{2} \mathrm{O}-\mathrm{Ag}_{2} \mathrm{O}$ system. J Mater Res Technol 8:1003-1013

27. Gaafar MS, Marzouk SY, Mahmoud IS, Al-Zobaidi S (2015) Simulation of acoustic properties of borate and tellurite glasses. Int Sch Sci Res Innov 9:1858-1867

28. El-Moneim AA (2019) Oxyfluoro-zinc-tellurite glasses - Part I: predicting the elastic properties and glass transition temperature under the substitution of $\mathrm{AlF}_{3}$ by $\mathrm{ZnO}$. J Fluor Chem 217:97-104

29. Laopaiboon R, Laopaiboon J, Pencharee S, Nontachat S, Bootjomchai $C$ (2016) The effects of gamma irradiation on the elastic properties of soda lime glass doped with cerium oxide. J Alloys Compd 666:292-300

30. Januchta K, Youngman RE, Jensen LR, Smedskjaer MM (2019) Mechanical property optimization of a zinc borate glass by lanthanum doping. J Non-Cryst 520:119461

31. Gaafar MS, Marzouk SY, Zayed HA, Soliman LI, El-Deen AHS (2013) Structural studies and mechanical properties of some borate glasses doped with different alkali and cobalt oxides. Curr Appl Phys 13:152-158

32. Yousef ES, El-Adawy A, El-KheshKhany $\mathrm{N}$ (2006) Effect of rare earth $\left(\mathrm{Pr}_{2} \mathrm{O}_{3}, \mathrm{Nd}_{2} \mathrm{O}_{3}, \mathrm{Sm}_{2} \mathrm{O}_{3}, \mathrm{Eu}_{2} \mathrm{O}_{3}, \mathrm{Gd}_{2} \mathrm{O}_{3}\right.$ and $\left.\mathrm{Er}_{2} \mathrm{O}_{3}\right)$ on the acoustic properties of glass belonging to bismuth-borate system. Solid State Commun 139:108-113

33. Manupriya TKS, Sharma G, Rajendran V, Singh K, Gayathri Devi AV, Aravindan S (2003) Structural and acoustic investigations of calcium borate glasses. Phys Stat Sol (A) 203:2356-2364

34. Saddeek YB, Shaaban KHS, Aly KA, Farag RS, Uosif MAM (2015) Studying effect of $\mathrm{SiO}_{2}$ on elastic properties of glasses based on environmental tailings using a nondestructive ultrasonic method. Int J New Hor Phys 2:53-57

35. Vasantharani P, Rajeswari S (2017) Ultrasonic studies of physical and elastic properties of sodium borate glasses. Int R Res Appl Sci Eng Technol 5:2321-9653

36. Saddeek YB, Azooz MA, Kenawy SH (2005) Constants of elasticity of $\mathrm{Li}_{2} \mathrm{O}-\mathrm{B}_{2} \mathrm{O}_{3}$-fly ash: structural study by ultrasonic technique. Mater Chem Phys 94:213-220

37. Bootjomchai C, Laopaiboon J, Nontachat S, Tipparach U, Laopaiboon R (2012) Structural investigation of borosilicate recycledbarium-bismuth glasses under the influence of gammairradiation through ultrasonic and FTIR studies. Nucl Eng Des 248:28-34

38. Gao G, Hu Y, Jia H, Liub P, Du P, Xu D (2019) Acoustic and dielectric properties of epoxy resin/hollow glass microsphere composite acoustic materials. J Phys Chem Solids 135:109105

39. Bar AK, Kar T, Royan D, Bhattacharya S (2014) Vickers micro hardness measurement of glass nanocomposites. J Mat Sci Mech Eng $1: 18-22$

40. Shelby JE (2005) Introduction to glass science and technology. Royal Society of Chemistry, Cambridge

41. Singh S, Kalia G, Singh K (2015) Effect of intermediate oxide $\left(\mathrm{Y}_{2} \mathrm{O}_{3}\right)$ on thermal, structural and optical properties of lithium borosilicate glasses. J Mol Struct 1086:239-245

42. Popescu MA (2005) Medium range order in non-crystalline materials. J Ovonic Res 1:7-19

43. Alajerami YSM, Abushab KM, Alagha SI, Mhareb MHA, Saidu A, Qdaih F, Ramadan K (2017) Physical and optical properties of 
sodium borate glasses doped with $\mathrm{Dy}^{3+}$ ions. Int J Mod Phys B 31:1750171

44. Pal M, Roy B, Pal M (2011) Structural characterization of borate glasses containing zinc and manganese oxides. J Mod Phys 2:1062-1066

45. ElBatal FH, Ouis MA, ElBatal HA (2016) Comparative studies on the bioactivity of some borate glasses and glass-ceramics from the two systems: $\mathrm{Na}_{2} \mathrm{O}-\mathrm{CaO}-\mathrm{B}_{2} \mathrm{O}_{3}$ and $\mathrm{NaF}-\mathrm{CaF}_{2}-\mathrm{B}_{2} \mathrm{O}_{3}$. Ceram Int 42:8247-8256

46. Marzouk SY (2009) Ultrasonic and infrared measurements of copper-doped sodium phosphate glasses. Mater Chem Phys 114:188-193

47. Saddeek YB, Gaafar MS, Bashier SA (2010) Structural influence of PbO by means of FTIR and acoustics on calciumaluminoborosilicate glass system. J Non-Cryst 356:1089-1095

48. Kumar GR, Baskar SU, Rao MC (2018) Role of $\mathrm{Mn}^{2+}$ ions on opti$\mathrm{cal}$ and luminescent properties of $\mathrm{CaF}_{2}-\mathrm{Y}_{2} \mathrm{O}_{3}-\mathrm{ZnO}-\mathrm{B}_{2} \mathrm{O}_{3}-\mathrm{SiO}_{2}$ glasses. Results Phys 10:546-557

49. Kaur R, Bhatia V, Kumar D, Rao SMD, Singh SP, Kumar A (2019) Physical, structural, optical and thermoluminescence behavior of $\mathrm{Dy}_{2} \mathrm{O}_{3}$ doped sodium magnesium borosilicate glasses. Results Phys 12:827-839

50. Gaafar MS, Shaarany I, Alharbi T (2014) Structural investigations on some cadmium-borotellurate glasses using ultrasonic, FT-IR and X-ray techniques. J Alloys Compd 616:625-632

51. Gaafar MS, Afifi HA, Mekawy MM (2009) Structural studies of some phospho-borate glasses using ultrasonic pulse-echo technique, DSC and IR spectroscopy. Phys B 404:1668-1673

52. Abo-Naf SM (2012) FTIR and UV-VIS optical absorption spectra of gamma-irradiated $\mathrm{MoO}_{3}$-doped lead borate glasses. J NonCryst 358:406-413

53. Khalil EMA, ElBatal FH, Hamdy YM, Zidan HM, Aziz MS, Abdelghany AM (2010) Infrared absorption spectra of transition metalsdoped soda lime silica glasses. Phys B 405:1294-1300

54. Abdelghany AM, Ouis MA, Azooz MA, EllBatal HA (2013) Defect formation of gamma irradiated $\mathrm{MoO}_{3}$-doped borophosphate glasses. Acta A Mol Biomol Spectrosc 114:569-574

Publisher's Note Springer Nature remains neutral with regard to jurisdictional claims in published maps and institutional affiliations. 